\title{
EFFECT OF BIOPOLISHING ON WARM-COOL FEELING OF KNITTED FABRIC: A SUBJECTIVE AND AN OBJECTIVE EVALUATIONS
}

\author{
Asif Mangat, Lubos Hes, Vladimir Bajzik \\ Technical University of Liberec, Faculty of Textile Engineering, Liberec, Czech Republic, \\ e-mail: lubos.hes@gmail.com
}

\begin{abstract}
:
Soft and clean surface of fabric without any floating fibers is one of the factors important for better marketing of clothing. The most common method for having such clean fabric surface is the removal of protruding (floating) fiber from the surface of the fabric. Many studies have proved that enzymatic treatment, commonly called biopolishing, removes the floating fibers from the surface of fabric and gives a smooth surface to the fabric. This study is an effort to assess and measure the impact of biopolishing of knitted fabric through objective and subjective evaluation on warm-cool feeling of fabric because of change in surface profile of the fabric. For testing purposes, $31 \mathrm{knitted}$ fabric samples of various kinds were produced. Alambeta has been used for measuring thermal absorptivity values of fabric. Thermal absorptivity is an indicator of warm-cool feeling. For subjective evaluation, a group of 30 people were asked to give their opinion about warm-cool feeling. Both subjective and objective assessments confirm that biopolishing has a significant impact on warm-cool feeling. Fabric gives cool feeling after biopolishing. This study explores that clean surface will have higher thermal absorptivity and will give cool feeling when it will be touched by human skin.
\end{abstract}

\section{Keywords:}

Biopolishing, warm-cool feeling, thermal absorptivity

\section{Introduction}

Clothing made up of knitted fabric is commonly used as sports and casual wear because of its flexibility that helps in adopting body shape. Most of the undergarments are made using knitted fabric. Moreover, knitted fabric is also used to make players uniform because it provides minimum resistance during movement, which is called dynamic comfort. Knitted fabric is porous in nature and provides space to transfer moisture from the surface of human skin to environment and keeps skin dry. Dry skin is one of the fundamental requirements for thermophysiological comfort because moisture has higher thermal conductivity and helps in taking away the heat of the human body, which lowers the temperature of human body and creates a cool effect [1-3].

Surface of fabric determines the contact points between human skin and the fabric. More area of contact means more heat transfer through conduction. The surface of knitted fabric is not smooth as compare to woven fabric. It is due to its construction technology. Knitted fabric is made by suing loops, and there is quite uneven surface. Moreover, protruding fibers (fiber ends) are also present on the surface of knitted fabric, which play a crucial role in making contact between human skin and knitted fabric surface [2].

Yovanovich and Rohsenow [4] investigated the influence of surface roughness and waviness upon thermal contact resistance. The main objective of this study was to explore the phenomenon of thermal resistance between contacting solids. They explained that when two solid surfaces are put together under load, they actually touch at isolated micro contacts, and the resulting real area is the sum of these micro contacts. They further expressed that the micro contacts are restricted to a region called the contour area, which may cover a fraction of the total area. They further explained that in case of the nonuniform pressure distribution over the contour area provides micro contacts that has lot of variation in size and density. If there is no interstitial fluid and also we ignore heat transfer through radiation, all the heat flow will take place through the micro contacts. Work of Yovanovich and Rohsenow [4] is an evidence that heat flow between two solids put together having wavy surface depends on the micro contact points. If there is any change in the surface of the any solid, it will definitely change the micro contact points and ultimately heat flow will be affected. There is a significant change in the surface profile of fabric after the enzymatic treatment, which will change the overall contact area between two surfaces, fabric and hand, and heat flow will be affected.

\section{Biopolishing}

There are two ways to get smooth surface of knitted fabric; one to have yarn having very smooth surface and no protruding fibers and second to remove protruding fibers with the help 
of enzymes. This process is called biopolishing. During biopolishing, protruding fibers (extended ends of fiber) are removed and clean surface is created.

Özdil et al. have discussed in detail the use of enzymes for biopolishing [5]. They described that enzymes are widely used in biopolishing of cellulosic fabrics. Main objective of biopolishing is to remove the pills and fuzz from the fabric surface. It reduces the chances of pilling and also improves the shine of the fabric. During biopolishing, a cellulase enzyme carries out partial hydrolysis of cotton. Hydrolyzed cotton is washed off, and the surface of the fiber becomes less prone to pilling. On the other hand, some strength of the fabric is lost during the process, which takes place as a consequence of cotton removal and weight reduction.

Sarkar et al. [6] examined the impact of biopolishing on hand feel, tensile strength, seam strength, fabric weight, stiffness, dimensional stability, and color shade. They concluded that biopolishing exhibit a huge difference in the physical and mechanical properties of fabric.

Biopolishing is carried out during dyeing process. It may be performed before the dyeing process, during dyeing, or after dyeing. Amount of enzyme, time, and temperature depend on the type of enzyme, strength of enzyme, and required level of biopolishing. Most suitable recommended temperature is 60 ${ }^{\circ} \mathrm{C}$. Now many new enzymes are used for scouring and as well as for biopolishing $[6,7]$.

The primary objective of biopolishing is to have a fabric with smooth surface, which gives a smooth feeling when touched by hand. Owing to removing protruding fibers during biopolishing, contact points between human skin and fabric decreases because fabric is much smooth and plain while the surface of hand is quite uneven. Such change may alter the heat flow from human to the body of the fabric. Heat flow is one of the fundamental factors in determining the thermophysiological comfort.

Literature provides a number of studies about the change in shine, smoothness, and so on of fabric after biopolishing but there is no study about the change in warm-cool feeling of the fabric during initial touch. This study is an effort to measure the impact of biopolishing on warm-cool feeling of knitted fabric.

During biopolishing, protruding fibers on the surface of a fabric is cleaned off. It increases the contact points between the skin and the fabric. Increase in contact area will allow more heat to pass through the fabric. It shows that the fabric has the capacity to absorb heat from the surface to its other side. It will give a cool feeling. This study is an effort to measure the impact of biopolishing on thermal absorptivity using subjective and objective methods.

Figure 1 shows the surface of knitted fabric before biopolishing. A number of floating fibers are present on the surface. However, Figure 2 shows comparatively a clean surface because majority of the floating fibers have been removed from the surface during biopolishing process. This study identifies the impact of such change on warm-cool feeling, which is an important factor in clothing comfort as discussed by Hes [8].

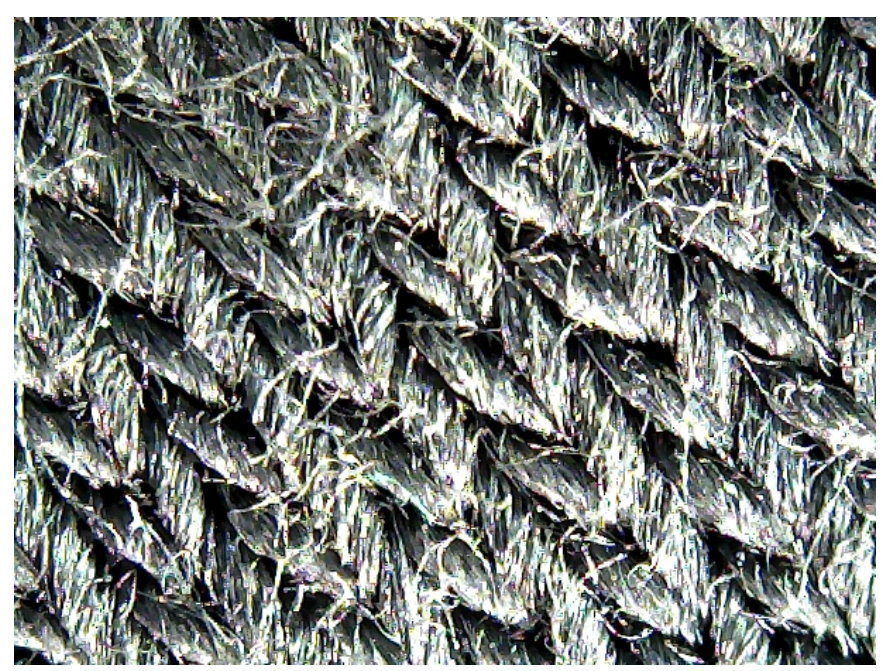

Figure 1. Knitted Fabric Before Biopolishing

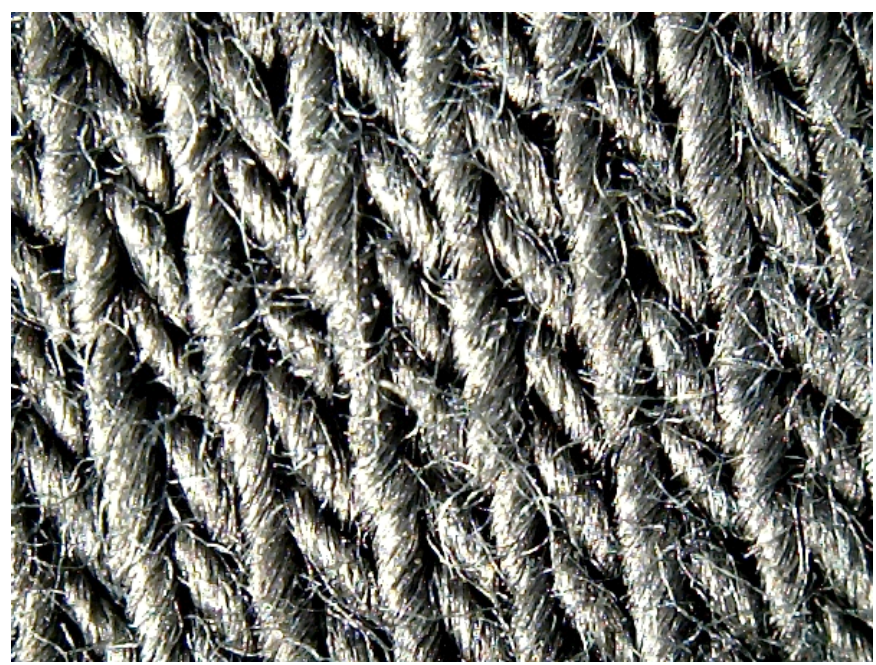

Figure 2. Knitted Fabric After Biopolishing

\section{Thermal absorptivity as an indicator of warm- cool feeling}

One of the essential purposes of clothing is protecting human skin from sudden changes in the atmospheric temperature. Thermal conductivity and thermal resistance are fundamental parameters of clothing. An alternate element that is connected with warm-cool feeling is thermal absorptivity.

Thermal absorptivity is a vital property of fabrics, and it is the subject to numerous studies. It relies on the thermal conductivity of fiber, thickness of material, and configuration of yarn and filaments as explained by Hes [9]. Hes used equation to measure thermal absorptivity [Equation 1]; in this equation, three parameters of fabric have been used: density, thermal conductivity, and specific heat. Hes further explained that thermal absorptivity demonstrates the capacity of a clothing material to give warm-cool feeling when that material is touched for a short period, less than two seconds. Any change in thermal conductivity and fabric thickness will change thermal absorptivity of a fabric, which is obvious 
from Equation 2. Obviously, a minor change in the structure may influence its thermal conductivity, for example, more dense fabric made of $100 \%$ polyester have higher amount of polyester and less amount of air trapped, such fabric will have higher thermal conductivity because thermal conductivity of polyester is $0.3-0.4\left[\mathrm{Wm}^{-1} \mathrm{~K}^{-1}\right]$ and thermal conductivity of air is $0.026\left[\mathrm{Wm}^{-1} \mathrm{~K}^{-1}\right]$. If a fabric is quite porous, which means less dense, then the amount of polyester will be less and air trapped will have higher ratio in fabric, which will decrease its thermal conductivity because of lesser thermal conductivity values of air. Thermal absorptivity of the wet fabric is always higher than the thermal absorptivity of a dry fabric, which means that it will create a cool feeling during its interaction with the human skin [3, 10-14].

The concept of thermal absorptivity (b) of fabrics was introduced by Hes [15], who discussed warm-cool feeling amid short contact between the human skin and the fabric surface. Given that the time of high-temperature contact $T$ between the human skin and the material is shorter than a few seconds, the mentioned fabric can be considered as a semiinfinite homogeneous mass with certain thermal capacity $\rho c$ $\left[\mathrm{Jm}^{-3}\right]$. Hes [15] further explained that unstable temperature field between the human skin (with steady temperature $\mathrm{t} 1$ ) and fabric have a relationship, which helps the heat to flow $\mathrm{q}\left[\mathrm{Wm}^{-2}\right]$ through the fabric:

$$
\begin{gathered}
q=\frac{b\left(t_{1}-t_{2}\right)}{\pi \tau^{0.5}} \\
b=\sqrt{\lambda \rho c}
\end{gathered}
$$

where $b$ represents the thermal absorptivity of fabrics $\left[\mathrm{Ws}^{0.5} \mathrm{~m}\right.$ $\left.{ }^{2} \mathrm{~K}^{-1}\right], \rho c\left[\mathrm{Jm}^{-3}\right]$ is the thermal capacity of the fabric, and the term $\lambda$ is the thermal conductivity $\left[\mathrm{Wm}^{-1} \mathrm{~K}^{-1}\right]$. The higher the thermal absorptivity of the fabric is, the cooler it will be in its feeling. This parameter ranges from $20 \mathrm{Ws}^{0.5} \mathrm{~m}^{-2} \mathrm{~K}^{-1}$ for fine nonwoven nets to $600 \mathrm{Ws}^{0.5} \mathrm{~m}^{-2} \mathrm{~K}^{-1}$.

Thermal absorptivity is an indicator of warm-cool feelings, which have been discussed widely in research studies and fabric production literature. Many researchers have elaborated its significance. Work of Oğlakcioğlu and Marmarali[5] is quite relevant to our study. They explained that warm-cool feeling is the first sensation. They concluded that higher thermal absorptivity of clothing gives a cooler feeling when it comes in contact with the human skin for the first time. The surface area between the fabric and skin is more smooth for fabric surfaces, and consequently, these structures create a cooler feeling Study of Marmarali proves that thermal absorptivity depends on the surface profile of the fabric. Smooth surface provides maximum contact points, and heat freely transfers between the skin and the fabric. More heat transfers mean higher thermal absorptivity and intensified warm-cool feeling.

Varga et al. [16] have studied physiological impact of resintreated fabrics including tencel and other cellulosic fibers. They included thermal absorptivity as one of the important parameters for thermophysiological comfort. Findings of Varga et al. show that thermal absorptivity of a fabric is an indicator of the amount of heat taken away from the surface of the fabric per unit time. In case if a fabric does not conduct heat from its surface, it will have warm feeling, which shows low thermal absorptivity. High thermal absorptivity values indicate cool feeling during the initial touch, which is not preferred for inner garments. Supuren et al. [17] investigated the moisture management and thermal absorptivity properties of double-face knitted fabrics. For this purpose, they used Alambeta.

\section{Experiment}

A group of 30 people (hand panel) were engaged (15 male and 15 female), with ages between 20 and 30 years. This group was asked to touch the fabric and give their opinion about warm-cool feeling, which they perceived within the initial two seconds.

For this purpose, 31 samples of 10 different kinds of knitted fabric were produced. All these samples were dyed simultaneously in yellow and kept free from any textile auxiliaries (softeners, etc.).

\section{Material}

For testing purposes, 31 knitted fabric samples of various kinds were produced using cotton and polyester-cotton combinations on circular knitting machines, which is used for knitting of weft knitting fabric. All samples were scoured and dyed simultaneously on a sample dyeing machine in yellow color using reactive and disperse dyes. Their thickness is same, approximately $2 \mathrm{~mm}$, after dyeing; the samples were grouped into two sets. One set was given cellulase enzyme treatment, which is produced by NOVO, and other set was kept untreated. Enzymes are proteins and large in size. There are many hundreds amino acids present. These amino acids take part in biochemical reaction at a certain temperature under specific $\mathrm{pH}$ conditions. Samples were treated with selected enzymes for 30 minutes at $60{ }^{\circ} \mathrm{C}$ in acidic conditions as per recommendations of the manufacturer.

\section{Investigation method}

Subjective and objective evaluation methods were applied to measure the impact of change in surface profile because of the enzymatic treatment on warm-cool feeling. For subjective evaluation, a group of 30 people were engaged. Alambeta was used for objective evaluation of thermal absorptivity, which is an indicator of warm-cool feeling.

Subjective evaluation is a process in which people are asked to express their feeling. There are a number of studies that have been conducted to measure the impact of any physical change in textile material through subjective evaluation [1823]. It shows its importance. Moreover, human being uses 
Table 1. Sample Details

\begin{tabular}{|c|c|c|c|c|}
\hline $\mathrm{Sr} \#$ & Fabric & Cotton (\%) & Polyester (\%) & GSM1 \\
\hline 1 & Single jersey & 100 & 0 & 180 \\
\hline 2 & Slub jersey & 100 & 0 & 115 \\
\hline 3 & Fleece & 60 & 40 & 230 \\
\hline 4 & Low-shrinkage fleece & 60 & 40 & 264 \\
\hline 5 & Pique & 60 & 40 & 272 \\
\hline 6 & Interlock & 50 & 50 & 176 \\
\hline 7 & Low-shrinkage fleece & 70 & 30 & 255 \\
\hline 8 & Single jersey & 60 & 40 & 125 \\
\hline 9 & Interlock & 100 & 0 & 177 \\
\hline 10 & Cut jersey & 80 & 20 & 185 \\
\hline 11 & Fleece & 100 & 0 & 293 \\
\hline 12 & Fleece & 80 & 20 & 241 \\
\hline 13 & Jersey & 80 & 20 & 232 \\
\hline 14 & Pique & 100 & 0 & 165 \\
\hline 15 & Single jersey & 80 & 20 & 176 \\
\hline 16 & Fleece & 100 & 0 & 257 \\
\hline 17 & Single jersey & 50 & 50 & 153 \\
\hline 18 & Pique & 100 & 0 & 157 \\
\hline 19 & Terry & 100 & 0 & 243 \\
\hline 20 & Thermal & 60 & 40 & 136 \\
\hline 21 & Pique & 100 & 0 & 201 \\
\hline 22 & Terry & 100 & 0 & 241 \\
\hline 23 & Fleece & 80 & 20 & 213 \\
\hline 24 & Pique & 100 & 0 & 241 \\
\hline 25 & Single jersey & 100 & 0 & 172 \\
\hline 26 & Single jersey & 100 & 0 & 175 \\
\hline 27 & Fleece & 70 & 30 & 213 \\
\hline 28 & Fleece & 50 & 50 & 269 \\
\hline 29 & Pique & 60 & 40 & 151 \\
\hline 30 & Slub fleece & 100 & 0 & 240 \\
\hline 31 & Single jersey & 100 & 0 & 219 \\
\hline
\end{tabular}

finally clothing. Feeling of human being about any clothing is much important for its acceptance in market. Finally, it confirms and rejects the results of measuring instrument.

\section{Subjective evaluation procedure}

Guideline provided in AATCC Evaluation Procedure 5: Fabric Hand: Guidelines for the Subjective Evaluation was followed. Bipolar observation technique was used to evaluate the changes caused by biopolishing. People were asked to give their observation about warm-cool feeling. Observers were given two sets of samples (treated and untreated) to tell which one is warmer. People were also given another option to mention if they found no difference between the feelings of both the samples.

Strict procedure was followed during conducting the subjective evaluation. Even minor changes in atmospheric temperature and humidity were recorded because they could create 
significant impact on the process and affect the final evaluation. Following procedure was adopted for subjective evaluation:

A laboratory equipped with air conditioner was selected. Temperature was kept between $25 \pm 2^{\circ} \mathrm{C}$ and relative humidity $(\mathrm{RH})$ humidity was maintained between $22 \%$ and $24 \pm 3 \%$. All samples were put in laboratory for 24 hours under uniform atmosphere.

A group of 30 students of postgraduate class (15 male and 15 female) were selected from a university. Their ages were between 20 and 25 years. Healthy, nonsmoking individuals having no skin problem were selected for testing.

Tests were conducted during a period of three hours. It was done to avoid any environment impact. Every individual was briefed and asked to wash and dry their hands according to the standard procedure. Samples were put on a table and people were asked to evaluate samples by rubbing, squeezing, touching, and giving their opinion on a sheet that was provided to each one of them.

\section{Objective evaluation}

Alambeta is now widely used for measuring thermal parameters, and it has been used to measure the thermal absorptivity [12, 24-26]. All samples were put in the laboratory for 24 hours. Every sample was measured five times to minimize the impact of any irregularity on measuring values.

\section{Results and discussion}

Table 2 shows the values of thermal absorptivity of 31 samples. Paired sample t test was applied to measure the significance of means of the two sets of values. Tables 3 and 4 show that statistically significant difference was found between the two sets of values. As discussed earlier, thermal absorptivity of samples before and after enzyme treatments were measured. In both the cases, the material used was the same. The only obvious difference existed in the surface profile, which was created by using enzymes. Enzymes remove protruding fibers and provide smoother surface. It shows the behavior of fabric if its surface is modified with the help of enzymes. Moreover, mean value of thermal absorptivity of treated fabric is $157 \mathrm{Ws}^{1 / 2} \mathrm{~m}^{-2} \mathrm{~K}^{-1}$ and mean value of untreated fabric is 162 $\mathrm{Ws}^{1 / 2} \mathrm{~m}^{-2} \mathrm{~K}^{-1}$ (Table 3). Table 4 shows $\mathrm{p}$-value $(0.043)$, which measures the significance of difference in a two-tailed test. This value is less than 0.05 , which proves that there is a significant difference between the two sets of values. This discussion shows that enzyme application makes the surface smoother and decreases the thermal absorptivity of the fabric. Moreover, the decrease in thermal absorptivity values is a sign of cool feeling as discussed by Hes [15].

\section{Subjective evaluation data also proves the fact}

A group of 30 people were engaged to give their feeling about warm-cool of the samples. They were provided with a set of two
Table 2. Thermal absorptivity [Ws $1 / 2 / \mathrm{m} 2 \mathrm{~K}]$, untreated and treated with enzymes

\begin{tabular}{|c|c|c|}
\hline $\begin{array}{c}\text { Sample } \\
\#\end{array}$ & $\begin{array}{l}\text { Thermal absorptivity } \\
\text { (untreated) }\end{array}$ & $\begin{array}{c}\text { Thermal absorptivity } \\
\text { (treated with } \\
\text { enzymes) }\end{array}$ \\
\hline 1 & 183 & 156 \\
\hline 2 & 136 & 132 \\
\hline 3 & 167 & 160 \\
\hline 4 & 155 & 161 \\
\hline 5 & 203 & 183 \\
\hline 6 & 133 & 138 \\
\hline 7 & 161 & 161 \\
\hline 8 & 145 & 144 \\
\hline 9 & 163 & 154 \\
\hline 10 & 134 & 152 \\
\hline 11 & 161 & 167 \\
\hline 12 & 179 & 185 \\
\hline 13 & 121 & 126 \\
\hline 14 & 157 & 126 \\
\hline 15 & 161 & 162 \\
\hline 16 & 176 & 188 \\
\hline 17 & 141 & 146 \\
\hline 18 & 162 & 158 \\
\hline 19 & 152 & 149 \\
\hline 20 & 130 & 111 \\
\hline 21 & 181 & 177 \\
\hline 22 & 192 & 144 \\
\hline 23 & 167 & 16.5 \\
\hline 24 & 172 & 164 \\
\hline 25 & 156 & 125 \\
\hline 26 & 189 & 142 \\
\hline 27 & 153 & 148 \\
\hline 28 & 179 & 180 \\
\hline 29 & 159 & 141 \\
\hline 30 & 184 & 172 \\
\hline 31 & 170 & 161 \\
\hline
\end{tabular}

samples: one treated with enzymes and the other untreated. They were asked: "Which sample gives a warmer feeling?" They were also provided with option that they could tell if they found no difference. Table 5 depicts that $43 \%$ evaluators felt that the enzyme-treated fabric gives warm feeling and $32 \%$ of them felt that untreated fabric gives warm feeling and $25 \%$ evaluators said that they felt no difference between the enzyme-treated 
Table 3. Paired Sample Statistics (Thermal absorptivity)

\section{Paired Samples Statistics}

\begin{tabular}{|c|c|c|c|c|c|}
\hline \multicolumn{2}{|c|}{} & Mean & N & $\begin{array}{c}\text { Standard } \\
\text { deviation }\end{array}$ & $\begin{array}{c}\text { Standard } \\
\text { error mean }\end{array}$ \\
\hline \multirow{2}{*}{ Pair 1} & Thermal absorptivity $\left[\mathrm{Ws}^{1 / 2} / \mathrm{m}^{2} \mathrm{~K}\right]$, untreated & 162.0000 & 31 & 19.68417 & 3.53538 \\
\cline { 2 - 6 } & Thermal absorptivity $\left[\mathrm{Ws}^{1 / 2} / \mathrm{m}^{2} \mathrm{~K}\right]$, treated with enzymes & 149.3387 & 31 & 31.03530 & 5.57410 \\
\hline
\end{tabular}

Table 4. Paired Sample Correlation (thermal absorptivity)

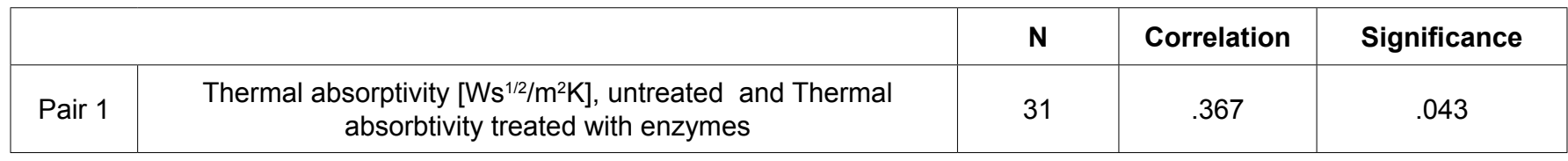

Table 5. Subjective Evaluation (Warm Feeling and No Difference)

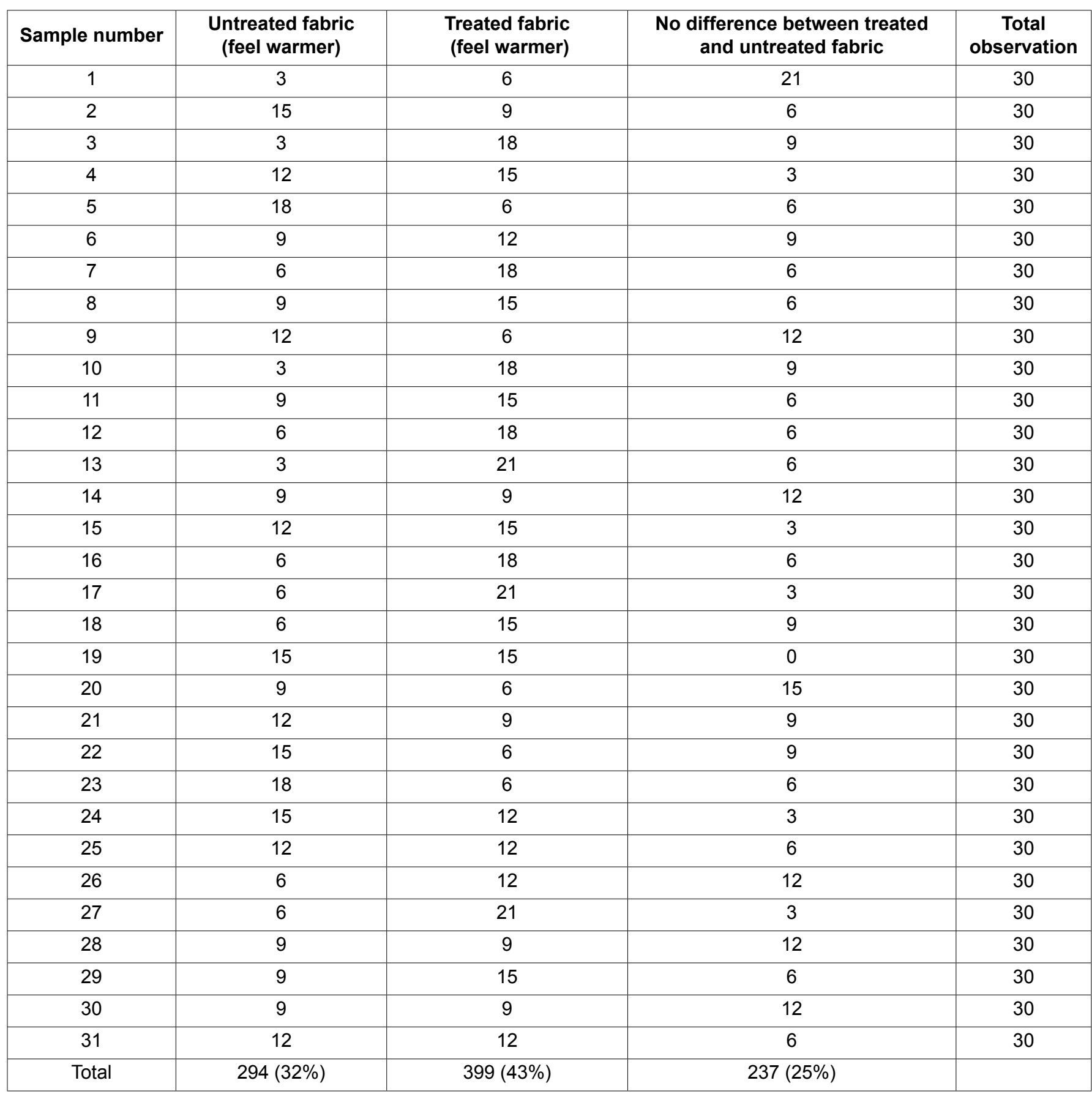


and untreated fabrics. Subjective evaluation shows that that the enzyme-treated fabric gives warmer feeling. It might be due to the contact points. Smooth surface provides less contact points with the skin when a hand is put on it. Human hand is quite uneven, and when it touches an even surface, there is a possibility of less contact area, which provides an area to transfer heat from the human body. Our subjective evaluation confirms the objective evaluation measured using Alambeta.

Table 6. Paired Sample Correlation for Warm-Cool Feeling

\begin{tabular}{|c|c|c|c|c|}
\hline \multicolumn{2}{|c|}{} & N & Correlation & Significance \\
\hline Pair 1 & $\begin{array}{c}\text { Untreated } \\
\text { fabric and }\end{array}$ & 31 & -.586 & .001 \\
\hline & $\begin{array}{c}\text { Treated with } \\
\text { Enzymes }\end{array}$ & & & \\
\hline
\end{tabular}

\section{Conclusion}

Warm-cool feeling is one parameter that is much noticed by the users during a touch between fabric and human skin. This property is called thermal absorptivity. There are many factors that determine the thermal absorptivity. People prefer smooth surface of fabric while selecting any garment. Industry uses enzymes to make fabric surface much smoother and to minimize the chance of pills on surface. This enzymatic treatment is called biopolishing. This is an effort to measure the impact of biopolishing using enzymes on thermal absorptivity of a fabric. For testing purpose, 31 samples of different kinds of knitted fabric were produced. One set was treated with enzymes to do biopolishing for a smooth surface, while the other set was kept untreated. Alambeta was used to measure the thermal absorptivity of both sets. For subjective evaluation, a group of 30 people were asked to give their opinion about warm-cool feeling by touching the fabric. Data was analyzed to find the significant difference in two sets of values. Both objective and subjective evaluations show that there is a significant difference between the enzyme- treated and untreated fabrics. Alambeta results prove that fabric treated with enzymes have smooth surface and gives warm feeling, and it was also endorsed by subjective evaluation. This study proves that biopolishing is a process that smoothens a fabric surface and creates warm feeling, which is a users' preference. It is mainly due to the decrease in contact points between hand and fabric during initial touch.

\section{References}

[1] Kovar, R., Angelova, Y., and Kyosev, Y., Evaluation of The Elastic Behaviour of Knitted Fabric. Vlákna a textil 2005. 12(1): p. 13-17.

[2] Oğlakcioğlu, N., \& Marmarali, A. , Thermal Comfort Properties of Some Knitted Structures. FIBRES \& TEXTILES in Eastern Europe 2007. 15(5-6): p. 64-65.

[3] Özdil, N., Marmaralı, A., and Kretzschmar, S.D., Effect of yarn properties on thermal comfort of knitted fabrics. International Journal of Thermal Science, 2007. 46(12): $p$. 1318-1322.
[4] Yovanovich, M.M., Rohsenow, W. M., Influence of surface roughness and waviness upon thermal contact resistance, 1967, Department of Mechanical Engineering, Engineering Projects Laboratory, Massachusetts Institute of Technology.

[5] Oğlakcioğlu, N., \& Marmarali, A., Thermal Comfort Properties of Some Knitted Structures. FIBRES \& TEXTILES in Eastern Europe 2007. 15(6): p. 64-65.

[6] Sarkar, J., Khalil, E., Solaiman, Md., Effect of Enzyme Washing Combined With Pumice Stone on the Physical, Mechanical and Color Properties of Denim Garments International Journal of Research in Advent Technology, 2014. 2(9): p. 65-68.

[7] Mazumder, S., Effects of Sand Blasting With Industrial Enzyme Silicon Wash on Denim ApparelCharacteristics. Daffodil International University Journal of Science And Technology, 2010. 5(1): p. 6-9.

[8] Hes, L. Fundaments of design of fabrics and garments with demanded thermophysiological comfort. in International Round Table «Clothing Comfort - Condition of Life Quality» 2009. Romania

[9] Hes, L., Fast Determination of Surface Moisture Absorptivity of Smart Underwear Knits, in International Textile ConferenceTerrassa2001.

[10] Crow, R.M., Heat and moisture transfer in clothing systems. Transfer through materials, a literature review Part 1. 1974, Ottawa: Ontario: Defence Research Establishment.

[11] Hes, L., and Loghin, C., Heat, moisture and air transfer properties of selected woven fabrics in wet state. Journal of Fiber Bioengineering and Informatics, 2009. 2(3): p. 141-149.

[12] Militky, J., Prediction of Textile Fabrics Thermal Conductivity, in Thermal Manikins and Modelling, J. Fan, Editor. 2006.

[13] Yoshihiroa, Y., Hiroakia, Y. and Hajimeb, M. , Effective thermal conductivity of plain weave fabric and its composite. Journal of Textile Engineering 2008; 54(4), 2008. 54(4): $p$. 111-119.

[14]Zhu, F., Zhang, W., Song, G., Thermal Performance Assessment of Heat Resistant Fabrics Based on a New Thermal Wave Model of Skin Heat Transfer. International Journal of Occupational Safety and Ergonomics 2006. 12(1): p. 43-51.

[15] Hes, L., Non-destruction determination of comfort parameters during marketing of functional garment and Apparels. Indian Journal of Fiber and Text. Research, 2008(33): p. 239-245.

[16] Varga, K., Kljun, A., Noisternig, M. F. Ibbett, R.N., Gruber, J., Schlangen, J. Griesser, U.J., Schuster, K.C., Physiological investigation of resin-treated fabrics from tencel and other cellulosic fibres. Lenzinger Berichte, 2009. 87: p. 135-141.

[17] Supuren, G., Oglakcioglu, N., Ozdil, N., Marmarali, A., Moisture management and thermal absorptivity properties of double-face knitted fabrics. Textile Research Journal, 2011. 81(13): p. 1320-1330.

[18] Dobilaitë, V. and A. Petrauskas, Analysis of Fabric Tailorability Subjective Evaluation. FIBRES \& TEXTILES in Eastern Europe, 2002. 10, No.3(38): p. 53-55.

[19] Li, M., et al. Factor Analysis on Subjective Attributes Affecting Knitted Fabric's Comfort Sensation. in First International Workshop on Database Technology and Applications. 2009 
[20] Mangat, M.M., V. Bajzik, and L. Hes, Influence of Cationic and Silicone Softeners and Weft Variation on Thermal and Sensorial Characteristics of Denim Subjective and Objective Evaluation, in COVITEX 20112011: Pakistan.

[21] Ozcelik, G., Supuren, G., Tulay, G., \& Tarakcioglu, I. , A Study on Subjective and Objective Evaluation of the Handle Properties of Shirt Fabrics. FIBRES \& TEXTILES in Eastern Europe, 2008. 16(3-68): p. 52-62.

[22] Ozcelik, G., et al., A Study on Subjective and Objective Evaluation of the Handle Properties of Shirt Fabrics. FIBRES \& TEXTILES in Eastern Europe July / September Vol. , No. , 2008. 16(3 (68)): p. 56-62.

[23] Plante, A.M., Holcombe, B.V., Stephens, L.G. , Fiber Hygroscopicity and Perceptions of Dampness: Part I: Subjective Trials. Textile Research Journal 65, 293-298., 1995.
[24] Abbasi, A.M.R., Mangat. M. M., Baheti, V. K., and Militky, J., Electrical and Thermal Properties of Polypyrrole Coated Cotton Fabric. Journal of Fibres and Textile., 2012. 1: p. 48-52.

[25] Karaca, E., Kahraman, N., Omeroglu, S., and Becerir, B., Effects of Fiber Cross Sectional Shape and Weave Pattern on Thermal Comfort Properties of Polyester Woven Fabrics. FIBRES \& TEXTILES in Eastern Europe, 2012. 20(3(92)): p. 67-72.

[26] Rengasamy, R.S., Das B.R., Patil, Y.B. , Thermophysiological comfort characteristics of polyester air-jettextured and cotton-yarn fabrics The Journal of The Textile Institute., 2009. 100(6): p. 507-511. 